\title{
As ações profissionais da/o assistente social na atenção primária em saúde no contexto da pandemia de Covid-19
}

Keli Regina Dal Pra ${ }^{1}$

https://orcid.org/0000-0002-1470-7811

Bruno Gonçalves Gavião ${ }^{2}$

https://orcid.org/0000-0003-0752-6235

Karina da Silva Rocca ${ }^{3}$

https://orcid.org/0000-0002-7294-9229

\author{
Luíza Soares Gutterres Lima ${ }^{4}$ \\ https://orcid.org/0000-0002-3376-8687 \\ Suzane Pereira da Cruz Alves Santos ${ }^{5}$ \\ https://orcid.org/0000-0002-8476-386X
}

${ }^{1}$ Universidade Federal de Santa Catarina, Departamento de Serviço Social, Programa de Pós-Graduação em Serviço
Social, Programa de Residência Multiprofissional em Saúde da Família, Florianópolis, SC, Brasil
${ }^{2}$ Universidade Federal de Santa Catarina, Programa de Residência Multiprofissional em Saúde da Família, Florianópolis, SC, Brasil
${ }^{3}$ Universidade Federal de Santa Catarina, Programa de Residência Multiprofissional em Saúde da Família, Florianópolis, SC, Brasil
${ }^{4}$ Universidade Federal de Santa Catarina, Programa de Residência Multiprofissional em Saúde da Família, Florianópolis, SC, Brasil
${ }^{5}$ Universidade Federal de Santa Catarina, Programa de Residência Multiprofissional em Saúde da Família, Florianópolis, SC, Brasil

As ações profissionais da/o assistente social na atenção primária em saúde no contexto da pandemia de Covid-19

Resumo: $\mathrm{O}$ artigo sistematiza as ações das/os Assistentes Sociais vinculadas/os a um curso de residência multiprofissional em saúde da família cuja atuação ocorreu na Atenção Primária em Saúde (APS), durante a pandemia do novo coronavírus, num contexto de reorganização dos serviços de saúde e do trabalho das/os profissionais do setor. Pretende-se contribuir com as reflexões sobre a dimensão técnico-operativa da Profissão abordando aspectos do trabalho no Núcleo Ampliado em Saúde da Família (NASF) neste período de excepcionalidade. A sistematização foi realizada a partir dos registros em diários de campo elaborados pelas/os profissionais entre os meses de março a setembro de 2020. Os principais resultados indicam que a crise sanitária aprofundou as desigualdades sociais demandando ações profissionais predominantemente socioeducativas voltadas ao acesso da população aos serviços e direitos sociais que amparam e oferecem condições de vida diante das mudanças provocadas pela pandemia. A reorganização requerida no processo coletivo de trabalho nos serviços de saúde implicou em alterações dos fluxos de acesso aos serviços e direitos sociais. Significa que, no período analisado, predominaram demandas profissionais de gestão e planejamento seja envolvendo a elaboração de materiais informativos de suporte às ações educativas, divulgação de informações pertinentes à população usuária do SUS, bem como de instrução às equipes multiprofissionais quanto aos benefícios sociais disponibilizados para mitigar os efeitos da pandemia. As ações socioeducativas voltadas para mobilização e assessoria político-organizativas apresentaram-se imprescindíveis para concretizar o acesso às práticas coletivas de controle social atentas à universalidade do direito à saúde.

Palavras-chave: Serviço Social. Ações Profissionais. Atenção Primária em Saúde. Pandemia Covid-19.

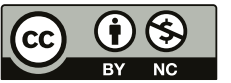

Este é um artigo publicado em acesso aberto (Open Access) sob a licença Creative Commons Attribution NonCommercial, que permite uso, distribuição e reprodução em qualquer meio, sem restrições desde que sem fins comerciais e que o trabalho original seja corretamente citado. 


\section{Professional actions of social assistants in primary healthcare in the context of the Covid-19 pandemic}

Abstract: This article systematizes the actions of social assistants associated to a multi-professional residency course in family health, undertaken within the Primary Healthcare System, during the new coronavirus pandemic, in a context of reorganization of healthcare services and the labor of professionals in the sector. Its objective is to contribute to reflections about the technical-operative dimension of the profession, addressing aspects of work by the Expanded Family Healthcare Nucleus in this exceptional period. The systematization was conducted through registers in field diaries prepared by the professionals from March to September 2020. The main results indicate that the sanitary crisis deepened social inequalities, requiring predominantly educational professional actions aimed at the population's access to social rights and services that support better living conditions, considering changes provoked by the pandemic. The reorganization required in the collective work process in healthcare services involved alterations in the flows of access to social services and rights. This means that, in the period analyzed, there was a predominance of professional demands related to administration and planning, that involved the elaboration of informative materials to support educational actions, the promotion of pertinent information to the population that uses Brazil's federal public single healthcare system, and providing instructions to multi-professional teams about social benefits available to mitigate the effects of the pandemic. The socio-educational actions aimed at mobilization and political-organizational assistance were essential to realizing access to collective practices of social control focused on the universal right to healthcare.

Keywords: Social Service. Professional Actions. Primary healthcare. Covid-19 pandemic.

Recebido em 19.10.2020. Aprovado em 16.05.2021. Revisado em 20.06.2021.

\section{Introdução}

Desde fevereiro de 2020, a vida cotidiana da população brasileira passa por profundas modificações na sua organização. O Estado de Emergência em Saúde Pública de Importância Nacional (ESPIN), decretado pela Portaria n. 188, de 3 de fevereiro de 2020 do Ministério da Saúde (MS, 2020) em decorrência da infecção humana pelo novo coronavírus (Covid-19) acarretou mudanças significativas em importantes atividades como: educação (suspensão do ensino presencial em grande parte das instituições); transporte coletivo (ora suspensão total, ora parcial), organização de parte das atividades de trabalho para home office, teletrabalho e trabalho remoto, e dos serviços de saúde prioritariamente voltados para o atendimento das demandas advindas da Covid- 19.

A epidemia de Covid-19 e suas implicações impactaram o processo coletivo de trabalho das/os profissionais da saúde, exigindo que suas ações fossem repensadas e reorganizadas. É justamente sobre esse processo, com seus questionamentos e reflexões sobre o cotidiano dos serviços de saúde, que se pretende compartilhar a experiência de trabalho do grupo de Assistentes Sociais envolvidas/os na Residência Multiprofissional ${ }^{1} \mathrm{em}$ Saúde da Família (Remultisf) da Universidade Federal de Santa Catarina (UFSC). Este grupo é composto por residentes de primeiro e segundo anos (R1 e R2), preceptoras e tutora do referido curso, cada qual com uma inserção diferente nos serviços de Atenção Primária em Saúde (APS) da cidade de Florianópolis.

Tal inserção profissional está profundamente marcada por novas condições de trabalho que, no contexto da pandemia, foram acrescidas pelo fato de muitas/os das/os Assistentes Sociais pertencerem ao grupo de risco para Covid-19. Isto levou a diferentes combinações: carga horária total em regime de teletrabalho ${ }^{2} ;$ carga horária dividida em teletrabalho e atividades presenciais; e carga horária total em regime de trabalho presencial. Importa destacar que, esse grupo, como em outras residências, teve suas atividades relacionadas a formação teórica, de caráter presencial, suspensas para o calendário escolar de 2020.

A experiência a ser compartilhada refere-se aos cenários de prática vinculados a dois centros de saúde em dois distritos sanitários e as/os residentes estão sob supervisão das Assistentes Sociais preceptoras que trabalham no Núcleo Ampliado em Saúde da Família (NASF). A iniciativa desse artigo ocorre motivada pela necessidade em sistematizar o rol de ações profissionais desenvolvidas, destacando às particularidades do trabalho profissional de Assistentes Sociais no NASF durante a pandemia de Covid-19. Este é o lugar de escrita, por isso, sem pretensões de generalizar ou encerrar aqui o debate.

Para tanto, o artigo está estruturado em duas seções: 1) apontamentos sobre a reorganização da APS e do trabalho das/os Assistentes Socais no contexto da pandemia de Covid-19; e 2) sistematização das ações desenvolvidas pelo grupo de Assistentes Sociais da Residência junto ao NASF durante o período da pandemia. 


\section{Pandemia de Covid-19 e reorganização da atenção primária em saúde: o lugar das/os assistentes sociais}

Historicamente, a área da saúde se constitui em importante espaço de trabalho das/os Assistentes Sociais. A profissão se desenvolveu em consonância com o crescimento e expansão do Modelo Médico Assistencial Privatista (MENDES, 1995), vinculado especialmente ao sistema previdenciário (BRAVO, 2010). No entanto, o processo de Reconceituação da Profissão, a conjuntura de redemocratização política e a luta por direitos sociais que culminaram com a promulgação da Constituição Federal de 1988, fez com que as/os Assistentes Sociais passassem a reconhecer e a trabalhar com o compromisso de garantir o direito universal à saúde com uma inserção majoritária no Sistema Único de Saúde (SUS).

Com base no desenvolvimento da profissão no Brasil, indica-se que a inserção profissional na área da saúde concentra-se na atenção especializada do SUS, ou seja, tem-se um quantitativo maior de Assistentes Sociais trabalhando no âmbito secundário e terciário do que nos serviços de APS. A inserção profissional na APS ocorreu de forma heterogênea no território nacional, principalmente após a criação da Estratégia de Saúde da Família (ESF), com iniciativas isoladas de inserção nas equipes mínimas, principalmente porque ficou a cargo de cada município a complementação das equipes com outras categoriais profissionais (MARTINI; DAL PRÁ, 2018).

A realidade dessa inserção se reflete também no âmbito das residências multi e uniprofissionais em saúde, uma vez que os investimentos das últimas duas décadas voltaram a formação nessa modalidade de especialização para os níveis de maior complexidade do SUS. Sobre o Serviço Social nos programas de residência em saúde, o mapeamento realizado pela Associação Brasileira de Ensino e Pesquisa em Serviço Social (ABEPSS) demonstra que a profissão encontra-se inserida: principalmente nos programas de modalidade multiprofissional, criados a partir de 2009; em programas com áreas de concentração na saúde da criança/saúde do adolescente, seguidos por saúde do adulto e saúde mental e; em cenários de prática predominantemente hospitalares, com pequena parcela na ESF (CASTRO, 2013). Por esses motivos, reforça-se a importância de refletir sobre o trabalho desenvolvido pelas/os Assistentes Sociais no âmbito do NASF e de uma residência multiprofissional em saúde, especialmente no contexto da pandemia de Covid-19.

Antes de adentrar nas particularidades, ou seja, no miúdo do trabalho profissional, é fundamental indicar, mesmo que brevemente, que a crise em saúde instalada pela pandemia de Covid-19 soma-se a uma crise da APS, que no Brasil, acentua-se desde o início dos anos 2000 e se aprofunda com o golpe parlamentar de 2016, quando este nível de atenção passou a ser priorizado como alvo das terceirizações e privatizações. Para Matos (2020), o histórico desfinanciamento público, a disseminação por parte do setor privado da ideologia da impossibilidade da assistência pública à saúde de qualidade e as alterações no modelo de gestão do SUS (por organizações sociais, pela Empresa Brasileira de Serviços Hospitalares, por Fundações Estatais de Direito Privado etc.) interferem sobremaneira na conformação, por exemplo, da APS e consequentemente do próprio NASF.

As mudanças realizadas com o novo modelo de financiamento, imposto pelo Governo Federal, por meio da Política Nacional de Atenção Básica (PNAB) (BRASIL, 2017) e da Portaria n. 2.979/2019 (BRASIL, 2019) colocam em risco a universalidade do sistema (DAUMAS et al., 2020) e podem levar à extinção das atuais equipes NASF, pondo no colo das gestões municipais a responsabilidade em manter — diga-se financiar — este serviço. O fim do NASF significa também o desprivilegiamento da ESF “[...] e seu modelo assistencial com equipe multiprofissional e abordagem territorial e comunitária” (GHIRALDELLI; OLIVEIRA; MARTINS, 2020, p. 269). O NASF é, na imensa maioria dos municípios, a única possibilidade de contratação das/os Assistentes Sociais na APS, e mais que isso, dos serviços municipais abordarem, a partir do trabalho multi/ interdisciplinar, as determinações sociais do processo de saúde e doença.

A crise do financiamento mexe com questões caras ao modelo de APS brasileiro — que nunca escondeu sua perspectiva seletiva e focalizada advinda das orientações do Banco Mundial quando começa a se estruturar em meados da década de 1990 — , mas que diante de muitas contradições instituiu uma capacidade instalada que gerou mudanças na atenção à saúde das populações nunca priorizadas e que diante desta pandemia são impossíveis de serem ignoradas.

O regime de austeridade fiscal com o teto de gastos imposto pela Emenda Constitucional (EC) n. 95/2016 (BRASIL, 2016), deu brecha para uma importante mudança na organização da APS, onde o Ministério 
da Saúde deixa de ter a prerrogativa de induzir a adoção de políticas por meio de incentivos financeiros, como era o caso do NASF e outros programas nos quais os municípios recebiam recursos federais para implantar e manter esses serviços. A nova lógica passa a financiar os atendimentos realizados a partir da realidade de cada município. Os gestores passam a ter autonomia para priorizar serviços e ações de saúde que entenderem mais importantes no caso de queda da arrecadação de impostos e tributos em tempos de recessão econômica.

Estes apontamentos sobre o contexto macrossocietário da APS no Brasil, são o pano de fundo para que se entenda a realidade a ser refletida: o município de Florianópolis, o NASF e a residência multiprofissional em saúde da família em tempos da pandemia de Covid-19. Com a pandemia vieram as mudanças nos serviços de saúde, mas não só, pois os serviços das demais políticas sociais também foram impactados como, por exemplo, da assistência social, que se mostraram essenciais devido ao elevado grau de desigualdade social do País, onde milhões de brasileiros passaram à indigência devido à impossibilidade de trabalho contínuo. Viram-se milhões de pessoas sem renda em função do trabalho desprotegido, em condições precárias, sem proteção para situações de calamidade pública como a que se apresenta. Evidentemente as alterações mais significativas ocorreram nos serviços de saúde e para seus profissionais, pois o atendimento da população passou a ser direcionado prioritariamente aos casos de Covid-19. Em todo o País foi necessário "reorganizar os fluxos na rede de atendimento, redefinir os papéis das diferentes unidades e níveis de atenção e criar novos pontos de acesso ao sistema de saúde, especialmente por via remota" (DAUMAS et al., 2020, p. 2).

No caso da APS em Florianópolis a orientação foi privilegiar o teleatendimento para todos os pacientes sintomáticos respiratórios e também para as outras demandas. O município, ao longo dos anos, desenvolveu experiências de teleatendimento na rede que permitiu agilizar a atuação por meio dessa modalidade frente à pandemia de Covid-19 (SILVEIRA; ZONTA, 2020). A incorporação das Tecnologias da Informação e Comunicação (TIC) nos atendimentos em saúde passa a ser intensificada no contexto da pandemia, trazendo desafios importantes às/aos Assistentes Sociais, pois "repercute nos processos de trabalho [...], na relação com outras profissões e trabalhadores/as, na relação com usuários/as e nas condições éticas e técnicas de trabalho" (CONSELHO FEDERAL DE SERVIÇO SOCIAL, 2020, p. 2).

Inseridos nessa nova realidade, estão as/os Assistentes Sociais, que pela Resolução n. 218/1997 do Conselho Nacional de Saúde (BRASIL, 1997) são profissionais de saúde de nível superior. No âmbito do NASF, em Florianópolis, as/os profissionais que compõem o serviço tiveram os atendimentos individuais eletivos e atividades coletivas suspensas e passaram a atuar em duas principais frentes: nos centros de saúde e em outros postos de trabalho do setor (FLORIANÓPOLIS, 2020).

No caso da inserção das/os profissionais NASF nos centros de saúde, estas/es devem integrar sua organização colaborando nos serviços em funcionamento, nos esforços de combate à pandemia e nas atividades específicas de cada categoria (atendimentos de urgência, não presenciais, ações de cuidado aos trabalhadores dos centros de saúde, atividades organizacionais e apoio matricial a distância) (FLORIANÓPOLIS, 2020). As/os profissionais do NASF realizam parcela importante de seus atendimentos à população e às equipes de Saúde da Família (eSF) através de teleatendimento (SILVEIRA, ZONTA, 2020), seja a partir do domicílio ou institucionalmente onde são realizadas teleorientação, teleconsulta e telemonitoramento. Para o trabalho presencial nos centros de saúde, as/os profissionais adotaram como medida preventiva ao contágio concentrar a atuação nas unidades que possam acessar sem necessidade de transporte coletivo (no caso de não possuir meios próprios de locomoção); que ofereçam melhor estrutura de organização do trabalho coletivo e; com espaço físico para atendimentos individuais presenciais com segurança, para teletrabalho com garantia de sigilo e guarda do material de trabalho. Algumas destas medidas também foram relatadas por Oliveira et al. (2020) no caso do trabalho das/os profissionais NASF em Recife.

Nos casos de realocação, as/os profissionais NASF podem se integrar aos setores da Secretaria Municipal de Saúde (SMS), distritos sanitários ou postos de campanha, "[...] com tarefas específicas de acordo com as demandas locais" (FLORIANÓPOLIS, 2020).

Com a reorganização do NASF, alteram-se as rotinas das/os residentes multiprofissionais em saúde, a começar pela dinâmica das atividades teóricas sob responsabilidade da universidade. No calendário do ano letivo de 2020, as atividades teóricas foram reorganizadas para o formato não presencial a fim de evitar o contágio da comunidade universitária. $\mathrm{E}$ as atividades práticas passaram a ser realizadas observando questões importantes levantadas pelo Conselho Nacional de Saúde (CNS), pelo Fórum Nacional de Coordenadores de Residências em Saúde e pelo Fórum Nacional de Tutores e Preceptores: respeito ao limite de $80 \%$ da carga horária 
semanal para atividades práticas e teórico práticas; garantia de Equipamentos de Proteção Individual (EPI) a todas/os residentes no cenário de prática; ajuste na lotação da/o residente nos serviços que foram suspensos os atendimentos, assegurada capacitação mínima para atuar no novo serviço/setor; adequada distribuição das/os residentes nos cenários de prática, evitando a sua superlotação e orientação às/aos residentes sobre formas de contágio, plano de contingência local, atitudes de precaução, uso adequado e racional dos EPI (BRASIL, 2020; FÓRUM NACIONAL DE COORDENADORES DE RESIDÊNCIAS EM SAÚDE, 2020). As/os residentes em grupo de risco para Covid-19 foram afastadas/os das atividades presenciais e desenvolvem teletrabalho.

$\mathrm{E}$ as/os tutora/es e docentes vinculadas/os ao curso de residência passaram a desenvolver as atividades de acompanhamento das/os residentes remotamente, uma vez que foram suspensas as atividades presenciais. Este acompanhamento ocorreu sistematicamente por meio de aplicativos de mensagens e plataformas de videoconferência para viabilizar as reuniões de tutoria e o planejamento das ações da equipe. Também necessitaram reorganizar suas atividades para a modalidade não presencial a fim de viabilizar as aulas do calendário 2020 e as orientações dos Trabalhos de Conclusão de Curso (TCR).

Enfim, a situação de pandemia vivida no Brasil coloca como desafio às/aos Assistentes Sociais atuar dentro do "campo das suas competências profissionais e de suas atribuições privativas" (MATOS, 2020). A reorganização dos serviços de saúde numa atuação por força tarefa, tendo em vista a situação de emergência sanitária, por vezes, pressiona as/os profissionais a deslocarem-se da sua atuação específica. No entanto, o que se altera é a forma como ocorre este trabalho mantendo as atribuições privativas e competências profissionais (MATOS, 2020).

\section{Ações profissionais das/os assistentes sociais na atenção primária em saúde: o caso da residência multiprofissional em saúde da família}

Diante da pouca produção científica sobre a dimensão técnico-operativa do Serviço Social abordando aspectos do cotidiano das ações profissionais executadas na APS e no NASF, sistematiza-se a experiência do grupo de Assistentes Sociais em serviços de saúde no contexto da pandemia de Covid-19. Para tanto, analisa-se as demandas prevalentes e o conjunto de ações profissionais comumente desenvolvidas pelo prisma dos três processos interventivos propostos por Mioto e Lima (2009), uma vez que todo

[...] processo interventivo não se constrói a priori, ao contrário, faz-se no seu próprio trajeto, e essa construção não depende só do Assistente Social, mas também dos outros sujeitos envolvidos, dentre eles, o espaço socio-ocupacional no qual o profissional está inserido e os destinatários das ações nele desenvolvidas (MIOTO; LIMA, 2009, p. 27).

Parte-se da compreensão de que as ações profissionais são direcionadas e orientadas por "valores ético-morais e compromissos sociopolíticos, podendo contribuir para o fortalecimento de projetos societários vinculados aos interesses e necessidades da classe trabalhadora", mas como a realidade não é monolítica, a profissão também pode voltar-se a atender às demandas do capital. No caso das ações profissionais na área da saúde deve-se compreendê-las a partir da inserção no trabalho coletivo embasado pelo conceito ampliado de saúde e pelo reconhecimento das determinações sociais do processo saúde-doença (GHIRALDELLI; OLIVEIRA; MARTINS, 2020, p. 265).

Por isso, considera-se que é apropriado sistematizar as ações através de sua vinculação a processos interventivos, pois eles permitem um retrato tanto da diversidade quanto das particularidades da inserção das/os Assistentes Sociais em diferentes espaços socio-ocupacionais, evidenciando de maneira qualificada seus aportes teórico-técnicos e a atenção que dispensam à Lei de Regulamentação da Profissão (MIOTO; LIMA, 2009).

Assim, organiza-se o relato da experiência, caracterizando as ações desenvolvidas pelas/os Assistentes Sociais no NASF durante seis meses da pandemia de Covid-19 (de março a setembro de 2020). Conforme a proposta de Mioto e Lima (2009), a partir das características das demandas atendidas nos serviços pode-se reunir as ações em três processos interventivos que nos permite descrevê-las, destacando suas particularidades operacionais ao mesmo tempo em que se apreende a dialética que a materializa. 


\section{Demandas e ações em processos políticos-organizativos}

Inicia-se descrevendo as ações profissionais referentes aos processos político-organizativos ${ }^{3}$. Dadas suas características, trata-se de um rol de demandas coletivas dos segmentos organizados da sociedade civil em torno de pautas públicas de defesa e ampliação de Direitos, a saber: a) monitoramento dos debates encaminhados pelo Conselho Municipal de Saúde (CMS) através da articulação estabelecida pela equipe com sua Secretaria Executiva; b) assessoria técnica prestada a um Conselho Local de Saúde (CLS); e c) mobilização e sensibilização socioeducativa para participação política ativa de profissionais e usuários em fóruns de defesa do SUS.

Dentre as ações que atenderam ou deram suporte às demandas coletivas descritas, destaca-se as ações socioeducativas junto às instâncias de controle social porque se dedicam à problematização crítica do direito ao acesso integral e universal à saúde sob responsabilidade do Estado através de pactuações coordenadas e financiadas, sobretudo em contexto de pandemia. As atividades desenvolvidas junto ao CMS ocuparam-se em acompanhar e qualificar o debate político em torno das prioridades de saúde e ocorreram através da participação ativa em plataformas virtuais que propiciaram a execução de: plenárias; rodas de conversa com conselheiras/ os municipais, distritais e locais de saúde para o debate de diversos temas pertinentes (ex.: levantamento de dados e informações sobre as demandas do município e organização do processo de trabalho em cada serviço de saúde; os impactos da Covid-19; detalhamento de ações intersetoriais com os serviços de assistência social para o combate à Covid-19; monitoramento dessas ações pelo CMS, Conselhos Locais de Saúde e conselhos municipais da Assistência Social, Educação e da Mulher).

Concomitante às atividades no CMS, ocorreu a assessoria técnica para fortalecer o controle social de um CLS envolvendo: (i) ato público distanciado em reivindicação ao acesso à água; (ii) elaboração de documentos formalizando as reivindicações e envio para as instâncias responsáveis ao abastecimento de água; (iii) solicitação de caminhão pipa para abastecimento dos domicílios; (iv) suporte com informações sociojurídicas e elaboração de documentos necessários às solicitações por regularização fundiária, em particular para requer o reconhecimento oficial da comunidade pela Prefeitura, aspecto que regularizaria o fornecimento e o acesso à água, saneamento e coleta de lixo.

Motivadas/os pelos desafios presentes nessas demandas coletivas que conformam as ações em processos político-organizativos, as/os Assistentes Sociais engajaram-se na articulação técnica e política de fóruns de saúde: a) para rearticulação do Fórum Catarinense em Defesa do SUS e Contra as Privatizações (FCDSCP); e b) para a Frente Nacional contra a Privatização da Saúde (FNCPS) onde integram o colegiado gestor.

A participação nesses fóruns de luta pelo direito à saúde aumentou a atenção e o monitoramento do orçamento municipal através da participação na audiência pública virtual promovida pela Câmara Municipal de Vereadores que debateu a Lei de Diretriz Orçamentária (LDO) para o ano 2021.

\section{Demandas e ações em processos socioassistenciais}

O segundo rol de ações refere-se àquelas que compõem o atendimento às demandas singulares de indivíduos, grupos e/ou famílias. Trata-se das ações que estruturam os processos socioassistenciais ${ }^{4}$; neles o atendimento aos usuários ocorre de maneira direta e visa estimular sua autonomia nas relações institucionais e sociais (MIOTO; LIMA, 2009). No caso da APS, destacam-se as ações socioeducativas cujas metas consistiram em: tornar acessíveis para profissionais de saúde e usuárias/os informações sobre acesso aos serviços intersetoriais das políticas de assistência social, previdência social e trabalho e a reorganização dos fluxos de atendimento dos serviços de saúde em decorrência da pandemia de Covid-19 que potencializam o atendimento no SUS a partir do princípio da integralidade.

As demandas que caracterizam as ações socioeducativas foram atendidas dentro dos limites estabelecidos pelas autoridades sanitárias 5 . Assim, foram realizadas através de teletrabalho com o uso de aplicativos de mensagens e/ou videoconferências a fim de cumprir com o objetivo central de viabilizar os matriciamentos com as eSF e os atendimentos individuais com as/os usuárias/os dos serviços de saúde. Importante destacar que os atendimentos individuais se concentraram em uma série de orientações: 
a) às gestantes sobre realização de exames, consultas de pré-natal e acesso à rede de serviços socioassistenciais, pois as eSF foram orientadas a realizar busca ativa daquelas/es usuárias/os em situações de maior risco ou vulnerabilidade como as gestantes, usuárias para primeira consulta de puericultura e pacientes crônicos (SILVEIRA; ZONTA, 2020);

b) relacionadas aos benefícios e programas sociais como: condicionalidades do Programa Bolsa Família, acesso ao Benefício de Prestação Continuada (BPC), critérios e formas de acesso ao auxílio merenda e ao auxílio emergencial, este último exigiu da equipe decodificar as informações sobre suas alterações durante o período da pandemia, bem como compreender os motivos de recusa, pois inúmeras/os usuárias/ os encontraram dificuldades em ter suas solicitações atendidas;

c) relacionadas ao acesso aos direitos trabalhistas, em função das demissões e acordos de redução da jornada de trabalho; previdenciários como auxílio-doença, procedimentos relacionados a realização de perícia online, acesso aos seus resultados junto ao Instituto Nacional do Seguro Social (INSS) e inúmeras demandas caracterizando a inacessibilidade aos recursos remotos implantados pelo INSS durante o período da pandemia;

d) relacionadas ao funcionamento e fluxo dos serviços de saúde reorganizados durante a pandemia, especialmente sobre as campanhas de vacinação e os serviços oferecidos nos centros de saúde; monitoramento dos casos suspeitos de Covid-19 notificados pela Vigilância Epidemiológica a partir de ligações telefônicas para os usuários em situação de suspeita de contaminação a fim de obter informações sobre suas condições de saúde. Esta ação foi desenvolvida pelas/os residentes nos meses de março e abril até que o monitoramento fosse descentralizado para as eSF nos territórios das/os usuárias/os.

De modo geral, na pandemia, as ações socioeducativas em processos socioassistenciais referiram-se a três demandas principais: $1^{\mathrm{a}}$ ) atendimentos informativos relacionados à operacionalização do auxílio emergencial; $2^{a}$ ) atendimentos e encaminhamentos relacionados aos direitos trabalhistas (grande parte da população foi dispensada de seus postos de trabalho), e também sobre o acesso ao auxílio doença diante da interrupção do atendimento presencial nas agências do INSS; e $3^{\mathrm{a}}$ ) atendimentos por meio de orientações sobre acesso ao auxílio funeral e outros serviços de suporte ao agravos persistentes da doença decorrentes do agravamento da contaminação e da mortalidade por Covid-19.

Outro rol de demandas que estruturam os processos socioassistenciais refere-se às ações de natureza socioemergencial, prioritariamente relacionadas ao acesso à alimentação devido à insuficiência financeira da população usuária do SUS. Em determinados momentos, a equipe de Serviço Social foi demandada a distribuir alimentos arrecadados voluntariamente para as/os usuárias/os vulneráveis do território dos centros de saúde. O posicionamento profissional considerou que na política de saúde uma ação seletiva como a de estabelecer critérios para a distribuição de alimentos iria contrariamente aos princípios de universalidade do SUS e se caracterizaria como prática assistencialista. Como encaminhamento sugeriu-se uma integração intersetorial onde os alimentos arrecadados fossem direcionados para os serviços executores da política de assistência social porque neles já existe o cadastro e a identificação das famílias que necessitam do benefício eventual da cesta básica.

\section{Demandas e ações em processos de gestão e planejamento}

As demandas que configuram as ações profissionais em processos de gestão e planejamento envolvem tanto atividades de planejamento institucional quanto de planejamento profissional. No primeiro caso compreendem ações ligadas à gestão e gerência das diversas políticas sociais, das instituições e dos serviços sociais congregados a tais políticas. Trata-se de ações que as/os profissionais desenvolvem em cargos gerenciais e administrativos. Já o planejamento profissional compreende ações que organizam a intervenção específica, localizando-a no processo coletivo de trabalho em equipe. Os objetivos das ações em processos de gestão e planejamento implicam: efetivar práticas intersetoriais e gerir as relações interinstitucionais e as informações pertinentes às famílias, aos atendimentos ofertados e aos territórios. Nesse sentido, também são objetivos dessas ações: criar protocolos entre serviços, programas e instituições no conjunto das políticas sociais que servem de base tanto para o trabalho profissional específico como para a equipe da qual é parte; consolidar bases de dados e informações, alimentadas pela documentação do processo interventivo (diário de campo, prontuários de atendimento, estudos, relatórios); construir protocolos de atendimento e redes etc. (MIOTO; LIMA, 2009). 
Na pandemia de Covid-19, as atividades de planejamento institucional priorizaram: a elaboração de projetos coletivos e multiprofissionais que foram executados através de: (i) telegrupo com gestantes onde coube ao Serviço Social planejar os temas relacionados aos direitos sociais no período de gestação, maternidade e paternidade; (ii) cultivo comunitário de alimentos no territórios de atuação da eSF e; (iii) elaboração de roteiro psicossocial para o monitoramento de casos notificados por contaminação de Covid-19, de modo a garantir o registro qualificado dos aspectos socioeconômicos, da organização familiar e da saúde mental que constituem a vida das/os usuárias/os impactados pela pandemia.

Já as atividades de planejamento profissional compreenderam: a) elaboração de plano de trabalho do Serviço Social, visando organizar as orientações dadas pelas autoridades sanitárias, adequar e estabelecer o fluxo de atendimento profissional no contexto de pandemia; b) mapeamento de redes e articulação intersetorial realizados de maneira cooperada entre as equipes que compõem os serviços sociais das políticas de assistência e previdência social, visando dar suporte ao atendimento da população na área da saúde; c) delimitação das prioridades de atendimento direto a partir do estudo dos prontuários das/os usuários/as; d) elaboração de relatórios quanti-qualitativos dos atendimentos realizados pela equipe de Serviço Social (dados mapeados a partir dos registros em prontuário eletrônico), a fim de subsidiar planos de ação com a comunidade; e) registros das ações profissionais no sistema de prontuário eletrônico dos centros de saúde; e f) planejamento integrado entre as assistentes sociais do NASF e da residência multiprofissional em saúde da família por meio de reuniões permanentes de preceptoria, residentes e tutoria.

Outra ação que se impôs como prioridade para o planejamento profissional no contexto da pandemia de Covid-19 refere-se à gestão da informação, onde o rol de atividades envolveu a produção e divulgação de materiais informativos como: (i) cards sobre o funcionamento de serviços durante a pandemia: Serviço de Proteção Especial para Pessoas com Deficiência, Idosas e suas Famílias (SEPREDI), Varas de Infância e Juventude e Centro de Referência de Atendimento à Mulher em Situação de Violência (CREMV), sobre denúncias de violência contra a mulher, benefícios socioassistenciais disponíveis, as principais questões trabalhistas a partir das mudanças realizadas pelo Governo Federal e acesso ao auxílio emergencial e cartão merenda; (ii) conteúdos informativos referente aos direitos sociais das gestantes e das pessoas com HIV/AIDS; e (iii) vídeos com informações sobre os serviços e a situação de saúde durante a pandemia. Outro enfoque priorizado pelas/ os residentes para potencializar o acesso às informações ocorreu com o uso de diversificadas mídias sociais digitais, devido ao imediato alcance das/os usuárias/os. O uso das TICs, em especial as ferramentas digitais para a comunicação em massa, já era incentivado e utilizado nos centros de saúde ampliando os canais de comunicação entre as eSF e a população usuária, durante a pandemia esse uso foi ampliado e intensificado.

Importante destacar que a produção e divulgação de materiais informativos pelo grupo de Serviço Social foi sempre preocupada e atenta à linguagem utilizada para que as/os usuárias/os compreendessem organicamente as informações disponibilizadas pelas eSF, ocorrendo de maneira ágil e concomitante as inúmeras alterações de critérios incluídos na definição dos protocolos de prevenção, cuidado e atenção. O relato da equipe NASF de Recife também demonstrou um enfoque prioritário em ações de natureza socioeducativa em processos socioassistenciais cujo suporte essencial para que seu alcance contribua na orientação e na autonomia da população durante a pandemia depende das ações em processos de gestão e planejamento (OLIVEIRA et al., 2020).

\section{Considerações finais}

A crise sanitária, imposta pela pandemia de Covid-19, evidenciou as crises econômica e social vivida pelo País e acentuadas desde 2016 com o golpe parlamentar onde foram implementadas contrarreformas na direção da retirada de direitos sociais. O desfinanciamento das políticas sociais a partir da aprovação da EC n. 95/2016 e as profundas alterações advindas das reformas trabalhista e previdenciária agravaram a pobreza, a fome e o desemprego. Assim, a pandemia de Covid-19 fez com que se reconhecesse a dimensão social da crise sanitária, que não se apresenta isolada desses atos antecedentes.

Esse reconhecimento do social em meio à crise sanitária colocou em evidência a intervenção das profissões como o Serviço Social. Na área da saúde foram necessárias mudanças nos fluxos de atendimento em todos os níveis de atenção em função da prioridade de cuidados aos usuários com sintomas respiratórios graves, mas também houve uma demanda crescente, à medida que avançou a contaminação, de informações 
sobre os serviços sociais que pudessem oferecer o mínimo de suporte para a sobrevivência das/os usuárias/ os do SUS.

Desse modo, mesmo com as rotinas de trabalho modificadas devido à reorganização dos serviços de APS as/os Assistentes Sociais do NASF e da residência multiprofissional em saúde da família atuaram dentro de suas competências e atribuições profissionais, considerando os desafios impostos pela pandemia de Covid-19. A primeira preocupação foi garantir a segurança para o não contágio devido à exposição no trabalho em saúde por meio de acesso à EPI, espaço físico adequado para os atendimentos, meios de transporte para os locais de trabalho, condições de saúde mental para trabalhar diante de uma doença altamente contagiosa e condições de saúde que não caracterizassem grupo de risco para Covid-19. O isolamento social das/os profissionais em grupo de risco dividiu a equipe em diferentes inserções na execução da carga horária de trabalho como: teletrabalho integral, trabalho presencial integral e teletrabalho e trabalho presencial. O teletrabalho carece de reflexões específicas, pois no caso do Serviço Social não há regulamentação sobre seu uso. No entanto, pode-se indicar que na realidade de onde parte essa sistematização, há um direcionamento para que as/os profissionais de saúde adotem o teletrabalho (teleatendimento, teleconsulta, telemonitoramento), a partir do uso das TIC, em parte das atividades cotidianas.

A partir dessas condições de trabalho, as ações profissionais da equipe de Assistentes Sociais na APS foram sendo construídas. Identificou-se que, mesmo com profundas mudanças na rotina de trabalho dada pelos protocolos sanitários, onde foi necessária a interrupção de praticamente todos os atendimentos presenciais e sua reorganização para o formato de teletrabalho, foi fundamental que as ações compreendessem os três processos interventivos: socioassistencial, gestão e planejamento e político-organizativo.

No processo socioassistencial as demandas recaíram prioritariamente em ações socioeducativas pautadas no acesso da população aos diferentes programas, serviços e benefícios sociais disponibilizados pelas instâncias governamentais para suporte de renda das famílias, grupos e indivíduos que ficaram desempregados e ou perderam rendimentos com trabalhos autônomos, além dos atendimentos voltados a prestar informações sobre as novas rotinas e fluxos dos serviços de saúde. A reorganização desse conjunto de serviços e direitos sociais demandou ações no processo de gestão e planejamento institucional e profissional, uma vez que envolveu a elaboração de inúmeros materiais de suporte às ações educativas tanto para informar a população usuária do SUS, como para instrumentalizar o trabalho das eSF a fim de minimizar os efeitos da pandemia. A elaboração dos materiais educativos abrangeu diferentes formatos como vídeos, áudios, cards e documentos, a serem disponibilizados em diferentes espaços digitais. A dimensão socioeducativa também foi predominante quando se planejou as ações voltadas para mobilização e assessoria político-organizativas, pois muitas das decisões envolvendo o direito à saúde no contexto da pandemia passaram por práticas coletivas de controle social.

$\mathrm{O}$ desafio em todas as ações profissionais desenvolvidas no NASF e na residência multiprofissional em saúde da família foi garantir a saúde como um direito universal a ser executado pelo Estado, enfrentando para isso muitas iniciativas privatizantes (que compreendem as/os usuárias/os do SUS como responsáveis pelas soluções dos seus adoecimentos, desempregos, pobreza) e caritativas, uma vez que as ações solidárias se intensificaram como solução para as crises econômica, social e sanitária.

\section{Referências}

BRASIL. [Constituição (1988)]. Emenda Constitucional n 95, de 15 de dezembro de 2016. Altera o Ato das Disposições Constitucionais Transitórias, para instituir o Novo Regime Fiscal, e dá outras providências. Brasília, DF: Presidência da República, [2016]. Disponível em: http://www.planalto.gov.br/ccivil_03/Constituicao/Emendas/Emc/emc95.htm. Acesso em: 24 set. 2020.

BRASIL. Ministério da Saúde. Gabinete do Ministro. Portaria n. 188, de 3 de fevereiro de 2020. Declara Emergência em Saúde Pública de importância Nacional (ESPIN) em decorrência da Infecção Humana pelo novo Coronavírus (2019-nCoV). Diário Oficial da União, Brasília, DF, 2020. Disponível em: http://www.planalto.gov.br/ccivil_03/portaria/prt188-20-ms.htm. Acesso em: 5 maio 2020. BRASIL. Ministério da Saúde. Gabinete do Ministro. Portaria nº 2.979, de 12 de novembro de 2019. Institui o Programa Previne Brasil, que estabelece novo modelo de financiamento de custeio da Atenção Primária à Saúde no âmbito do Sistema Único de Saúde, por meio da alteração da Portaria de Consolidação nº 6/GM/MS, de 28 de setembro de 2017. Diário Oficial da União, Brasília, DF, 2019. Disponível em: https://www.in.gov.br/en/web/dou/-/portaria-n-2.979-de-12-de-novembro-de-2019-227652180. Acesso em: 24 set. 2020. 
BRASIL. Ministério da Saúde. Gabinete do Ministro. Portaria nº 2.436, de 21 de setembro de 2017. Aprova a Política Nacional de Atenção Básica, estabelecendo a revisão de diretrizes para a organização da Atenção Básica, no âmbito do Sistema Único de Saúde (SUS). Diário Oficial da União, Brasília, DF, 2017. Disponível em: https://bvsms.saude.gov.br/bvs/saudelegis/gm/2017/prt2436_22_09_2017. html. Acesso em: 24 jul. 2020.

BRASIL. Ministério da Saúde. Recomendação no 018, de 26 de março de 2020. Recomenda a observância do Parecer Técnico no 106/2020, que dispõe sobre as orientações ao trabalho/atuação dos Residentes em Saúde, no âmbito dos serviços de saúde, durante a Emergência em Saúde Pública de Importância Nacional em decorrência Doença por Coronavírus - COVID-19. Brasília, Conselho Nacional de Saúde, 2020. Disponível em: https://conselho.saude.gov.br/images/Recomendacoes/2020/Reco018.pdf. Acesso em: 12 maio 2020.

BRASIL. Ministério da Saúde. Resolução no 218, de 06 de março de 1997. Brasília, Conselho Nacional de Saúde, 1997. Disponível em: https://bvsms.saude.gov.br/bvs/saudelegis/cns/1997/res0218_06_03_1997.html. Acesso em: 12 maio 2020.

BRAVO, M. I. S. Serviço Social e reforma sanitária: lutas sociais e práticas profissionais. 3 ed. São Paulo: Editora Cortez, 2010.

CASTRO, M. M. C. O serviço social nos programas de residência em saúde: resultados iniciais do mapeamento da ABEPSS. Temporalis. Brasília: n. 26, 2013, p.153-171. Disponível em: https://periodicos.ufes.br/index.php/temporalis/article/view/5309. Acesso em: 13 ago. 2020.

CONSELHO FEDERAL DE SERVIÇO SOCIAL (CFESS). Teletrabalho e teleperícia: orientações para assistentes sociais. Conselho Federal de Serviço Social, Brasília, 2020. Disponível em: http://www.cfess.org.br/arquivos/teletrabalho-telepericia2020-nota.pdf. Acesso em: 13 ago. 2020.

DAUMAS, R. P. et al. O papel da atenção primária na rede de atenção à saúde no Brasil: limites e possibilidades no enfrentamento da COVID-19. Cad. Saúde Pública. Rio de Janeiro, v. 36, n. 6, p. 1-7, 2020. Disponível em: http://cadernos.ensp.fiocruz.br/csp/ artigo/1093/o-papel-da-atencao-primaria-na-rede-de-atencao-a-saude-no-brasil-limites-e-possibilidades-no-enfrentamento-daCOVID-19. Acesso em: 23 jul. 2020.

FLORIANÓPOLIS. Secretaria municipal de saúde. Guia de orientações para o enfrentamento da pandemia de COVID-19. Orientações voltadas à rede de Atenção Primária À Saúde (APS) de Florianópolis/SC. Prefeitura municipal de saúde de Florianópolis/SC, 2020. Não paginado. Disponível em: https://coremu.paginas.ufsc.br/files/2020/03/GUIA-DE-ORIENTAC\%CC\%A7O\%CC\%83ES_APS_ versa\%CC\%83o-2_15mar2020.pdf. Acesso em: 13 maio 2020.

FÓRUM NACIONAL DE COORDENADORES DE RESIDÊNCIAS EM SAÚDE. Fórum Nacional de Tutores e Preceptores. Documento orientador Pandemia do COVID-19. Brasília, 2020. Disponível em: http://www2.ebserh.gov.br/documents/221436/5033452/F\%C3\% B3rum+Nacional+de+Coordenadores+de+Resid\%C3\%AAncias+em+Sa\%C3\%BAde.pdf/a684c01e-4a70-4b2d-a3c1-e56f7cb221bc. Acesso em: 12 maio 2020.

GHIRALDELli, R.; OLIVEIRA, A.; MARTINS, M. C. O Serviço Social no Núcleo de Apoio à Saúde da Família. Serv. Soc. Rev., Londrina, v. 22, n. 2, 2020, p. 261-282. Disponível em: http://www.uel.br/revistas/uel/index.php/ssrevista/article/view/35535/27658. Acesso em: 11 ago. 2020.

MARTINI, D.; DAL PRÁ, K. R. A inserção do assistente social na atenção primária à saúde. Argumentum, Vitória, v. 10, n. 1, p. 118132, 2018. Disponível em: https://periodicos.ufes.br/argumentum/article/view/18648/13184. Acesso em: 18 ago. 2020.

MATOS, M. C. A pandemia da COVID-19 e o trabalho de assistentes sociais na saúde. In: LOLE, A.; STAMPA, I.; GOMES, R. L. (org.). Para além da quarentena: reflexões sobre crise e pandemia. Mórula Editorial: Rio de Janeiro, 2020. Não paginado.

MENDES, E. V. As políticas de saúde no Brasil nos anos 80: a conformação da reforma sanitária e a construção da hegemonia do projeto neoliberal. In: MENDES, E. V. (org.). Distrito Sanitário: o processo social de mudança das práticas sanitárias do Sistema Único de Saúde. 3. ed. São Paulo-Rio de Janeiro: HUCITEC-ABRASCO, 1995. p. 19-91.

MIOTO, R. C. T.; LIMA, T. C. S. A dimensão técnico-operativa do Serviço Social em foco: sistematização de um processo investigativo. Textos e Contextos, Porto Alegre, v. 8, n. 1, p. 22-48, 2009. Disponível em: https://revistaseletronicas.pucrs.br/ojs/index.php/fass/ article/view/5673/4126. Acesso em: 10 ago. 2020.

MIOTO, R. C. T.; NOGUEIRA, V. M. R. Sistematização, planejamento e avaliação das ações dos assistentes sociais no campo da saúde. In: MOTA, A. E. et al. (org.). Serviço social e saúde: formação e trabalho profissional. São Paulo: Cortez, 2006. p. 273-303. OLIVEIRA, M. A. B. et al. A prática do núcleo de apoio à saúde da família do Recife no enfrentamento à pandemia COVID-19. APS em Revista. Belo Horizonte, v. 2, n. 2, p. 142-150, 2020. Disponível em: https://apsemrevista.org/aps/article/view/96/64. Acesso em: 23 jul. 2020.

SILVEIRA, J. P. M.; ZONTA, R. Experiência de reorganização da APS para o enfrentamento da Covid-19 em Florianópolis. APS em Revista, Belo Horizonte, v. 2, n. 2, 2020, p. 91-96. Disponível em: https://apsemrevista.org/aps/article/view/122/57. Acesso em: 23 jul. 2020. 


\section{Notas}

1 As residências multiprofissionais e em área profissional da saúde, são cursos de pós-graduação lato sensu, voltados para a educação em serviço, em regime de dedicação exclusiva, realizados sob supervisão docente-assistencial e destinado às categorias profissionais que integram a área de saúde.

2 O termo aqui utilizado se refere àquele trabalho realizado, tendo como instrumentais as Tecnologias da Informação e Comunicação (TIC), dentro e fora do ambiente da instituição empregadora.

3 As ações profissionais nesse eixo objetivam encaminhar para a esfera pública as demandas dos sujeitos atendidos. Seu foco principal está em instrumentalizar a participação dos sujeitos, respeitando o potencial político e o tempo dos envolvidos. Consideram as necessidades imediatas, mas prospectam a construção de novos padrões de sociabilidade entre os sujeitos, porque estão guiadas pela premissa da democratização dos espaços coletivos e pela criação de condições para a disputa com outros projetos societários (MIOTO; LIMA, 2009).

4 Nos processos socioassistenciais estão presentes ações de natureza: pericial, socioemergencial, socioterapêutica e socioeducativa (MIOTO; NOGUEIRA, 2006; MIOTO; LIMA, 2009).

5 Às/aos profissionais NASF foram orientados a evitar atendimentos presenciais individuais e coletivos a não ser em situações de urgência, priorizando sua condição de saúde e segurança.

\section{Keli Regina Dal Prá}

Keli.regina@ufsc.br

Assistente Social. Doutora pelo Programa de Pós-Graduação em Serviço Social da Pontifícia Universidade Católica do Rio Grande do Sul (PUCRS).

Docente do Departamento de Serviço Social da Universidade Federal de Santa Catarina (UFSC).

\section{DSS/UFSC}

Rua Eng. Agronômico Andrei Cristian Ferreira, s/n - Trindade.

Florianópolis - SC - Brasil.

CEP: 88040-900.

\section{Bruno Gonçalves Gavião}

brunoggaviao@gmail.com

Assistente Social. Graduado pela Universidade Federal de Santa Catarina (UFSC). Residente do Programa de Residência Multiprofissional em Saúde da Família da Universidade Federal de Santa Catarina (UFSC).

\section{Karina da Silva Rocca}

karina.rocca12@gmail.com

Assistente Social. Graduada pela Universidade Federal de Santa Catarina (UFSC). Residente do Programa de Residência Multiprofissional em Saúde da Família da Universidade Federal de Santa Catarina (UFSC).

\section{Luíza Soares Gutterres Lima}

gutterres.luiza@gmail.com

Assistente Social. Graduada pela Universidade Federal do Rio Grande do Sul (UFRGS). Especialista pelo Programa de Residência Multiprofissional em Saúde da Família da Universidade Federal de Santa Catarina (UFSC).

\section{Suzane Pereira da Cruz Alves Santos}

suzane_cruz19@hotmail.com

Assistente Social. Graduada pela Universidade Federal do Rio de Janeiro (UFRJ). Especialista pelo Programa de Residência Multiprofissional em Saúde da Família da Universidade Federal de Santa Catarina (UFSC). 


\section{REMULTISF/UFSC}

Rua Delfino Conti, s/n - Trindade.

Florianópolis - SC - Brasil.

CEP: 88040-370.

\section{Agradecimentos}

Às Assistentes Sociais Preceptoras Gisele Cunha e Leandra Martinha Mariano, que realizam a supervisão das/os residentes de Serviço Social junto à Remultisf/UFSC sem medir esforços para consolidar a atuação profissional em defesa do Sistema Único de Saúde (SUS).

Agência financiadora

Não se aplica.

Contribuições das autoras

A primeira autora concebeu e redigiu o manuscrito. As/ os demais autoras/es coletaram as informações por meio de registro de atividades e complementaram as informações. Todas/os as/os autoras/es participaram da revisão do artigo. Aprovação por Comitê de Ética Não se aplica.

Consentimento para publicação

Consentimento das/os autoras/es.

\section{Conflito de interesses}

Não há conflito de interesses. 